\title{
Transformaciones territoriales y turismo: Bahía de Banderas y Nuevo Vallarta
}

Recibido: 09/06/17 · Aceptado: 18/08/17

\author{
Mariel Verónica Massé Magaña* \\ Neptalí Monterroso Salvatierra \\ Elva Esther Vargas Martínez \\ Universidad Autónoma del Estado de México
}

\section{RESUMEN}

La región de Bahía de Banderas, ubicada en la costa sur de Nayarit, cuenta con una amplia extensión de kilómetros de litoral, lo cual ha llamado la atención de capitales internacionales para instalar sus consorcios hoteleros y otros servicios complementarios, con la intención de generar un destino turístico receptor de una demanda principalmente extranjera con altos ingresos. Esto ha sido posible a través de un proceso histórico, que es planteado en el presente artículo con una metodología de análisis que involucra tres dinámicas: penetración, desterritorialización y acumulación, en las que interactúan el capital y el Estado sobre territorios específicos. La desterritorialización, como hallazgo clave, es la estrategia bajo la cual los actores sociales anteriores actúan para conseguir su objetivo: el aprovechamiento económico del territorio mediante la actividad turística. Esta, aparentemente amigable con el ambiente y generadora de beneficios para los pueblos locales, se ha desarrollado bajo los principios de acumulación originaria y reproducción ampliada: exclusión, segregación, despojo y privatización, lo cual produce beneficios únicamente para los prestadores de servicios internacionales que penetran en las naciones subdesarrolladas, por medio de un pacto estatal-corporativo a costa del despojo continuo de comunidades indígenas, rurales y campesinas.

Palabras clave: Transformación territorial, turismo, despojo, Bahía de Banderas, Nuevo Vallarta.

*Correos electrónicos: mari.masse@hotmail.com·n.monterrososalvatierra@gmail.com · elvacolegio@hotmail.com 


\section{Territorial transformations and tourism: Bahía de Banderas and Nuevo Vallarta}

Recieved: 09/06/17· Accepted: 18/08/17

Mariel Verónica Massé Magaña*
Neptalí Monterroso Salvatierra
Elva Esther Vargas Martínez
Autónoma del Estado de México

Abstract

The Banderas Bay region, located on the South Coast of Nayarit, has a long extension of coastline kilometers. This has attracted the attention of international capitals to install their hotel consortia and other complementary services with the intention of creating an international tourism site aimed at high economic income foreign visitors. This has been possible through an historical process, which is presented in this article using an analysis methodology that considers three dynamics: penetration, de-territorialization and accumulation, in which State and capital interact over specific territories. Deterritorialization, as a key finding, is the strategy under which the previous social actors act to achieve their purpose, the economic use of the territory through tourism. This strategy, apparently environmentally friendly and generator of benefits for local people, has developed under the original accumulation and expanded reproduction principles: exclusion, segregation, dispossession and privatization, which generates benefits only for international service providers who penetrate into underdeveloped nations, through a state-corporate pact at the expense of the continued dispossession of indigenous, rural and peasant communities.

Key words: Territorial transformation, tourism, dispossession, Bay of Banderas, Nuevo Vallarta.

*E-mails: mari.masse@hotmail.com·n.monterrososalvatierra@gmail.com

·elvacolegio@hotmail.com 


\section{Introducción}

La región de Bahía de Banderas, ubicada en el litoral de la costa sur de Nayarit, cuenta con una amplia extensión de kilómetros de costa y es sede de consorcios hoteleros internacionales como Four Seasons, Mayan Resorts, Marival, Riu, Sea Garden e Iberostar, entre otros; transportación y empresas de entretenimiento como Walt Disney. Actualmente el ejido Jarretadera se ve amenazado por un plan de construcción para un parque temático en manos de la compañía canadiense Cirque Du Soleil, junto al grupo privado Mayan. Este destino, como otros tantos, se basa en la flexibilidad temporal, especulación inmobiliaria y venta de servicios turísticos -en calidad de monopolio- dirigidos a una demanda de altos ingresos en busca del enriquecimiento privado (Turner y Ash, 1991). Es muy posible asegurar que las inversiones provenientes de divisas como el dólar encuentran menores costos de producción en los países periféricos y, debido al tipo de cambio, la venta de servicios en dólares, sin importar el origen de la demanda, genera la plusvalía.

El contexto rural anterior de esta región se fundaba en una producción agrícola de baja escala y autoconsumo, pero su geografía, aunada a la sobreacumulación de capitales en Puerto Vallarta y su cercanía a este, convirtieron a la región en objetivo de desarrollo económico -basado en la política de internacionalización del turismo (Lanfant, 1980)- para originar tantos flujos económicos como fuera posible. Por ello, se han encaminado todos los esfuerzos en los niveles nacional e internacional para que se reproduzca un modelo turístico dirigido hacia las costas, donde la generación de infraestructura a gran escala permite la concentración y maximización de ingresos. México, como país periférico, cuenta además con ciertas ventajas que favorecen la inversión extranjera: la dependencia con la banca internacional que estipula las reformas estructurales económicas, culturales, territoriales y políticas que debe seguir el Estado para el otorgamiento de préstamos; los bajos costos de producción de medios y fuerzas productivas; y una clase política al servicio de los empresarios a través de leyes más flexibles (Jiménez, 2010; Noorloos, 2013).

La política turística aplicada a las costas mexicanas se ha materializado con centros turísticos tradicionales como Acapulco en Guerrero, Veracruz, Manzanillo en Colima y Puerto Vallarta en Jalisco desde la década de los cincuenta; más tarde, entre la década de los setenta y ochenta, se crea el programa de los 
Centros Integralmente Planeados (CIP) como "polos de desarrollo" para dinamizar la economía de las regiones en espacios principalmente vírgenes con atractivos paisajes y belleza escénica a fin de reproducir el modelo de "sol y playa”. Los primeros cir fueron Cancún en Quintana Roo, Ixtapa-Zihuatanejo en Guerrero, Los Cabos y Loreto en Baja California Sur, y Bahías de Huatulco en Oaxaca. Después sería incorporado el estado de Nayarit, con los destinos de Sayulita, Costa Banderas, San Francisco-Lo de Marcos, Litibú-Punta Mita, Cruz de Huanacaxtle, Flamingos, Bucerías y Nuevo Vallarta. Específicamente LitibúPunta Mita, Flamingos y Nuevo Vallarta se han planeado para la concentración de consorcios hoteleros internacionales para la oferta de servicios turísticos de gran categoría dirigidos a las élites nacionales e internacionales (Rodríguez Wallenius, 2015).

Estos polos de desarrollo han sido planificados en forma tipo enclave, es decir, aislar los complejos de los contextos locales en la mayor medida posible y concentrar dentro de ellos todos los servicios requeridos por el turista (alojamiento, transportación, comercio y entretenimiento) de tal manera que al mismo tiempo se acaparen los ingresos en un tipo de monopolio de los servicios turísticos (Gibson, 2009). Al tiempo que hoy, esta región ha sufrido una importante transformación territorial con base en los mismos principios capitalistas: la separación de los productores de sus medios de producción, o sea, el despojo de los campesinos y sus tierras aunado a la privatización de estas.

Las posibilidades de que empresas de la industria turística puedan establecerse en suelo mexicano son gracias a la adopción de políticas, acuerdos y convenios internacionales mayormente enfocados a estrategias de generación de ingresos, inversiones, privatización y desregulación política estatal para permitir a los mercados mundiales determinar el ejercicio económico de los países (Gómez, 2008; Fernández, 2011), donde el turismo es más una actividad generadora de plusvalía a través del despojo, exclusión, segregación, explotación y privatización del territorio, dejando fuera de sus beneficios a las poblaciones locales.

Para exponer lo anterior, se plantea una metodología de análisis basada en tres dinámicas: penetración, desterritorialización y acumulación, donde se interrelacionan tres categorías clave: el Estado, el capital y el territorio (figura 1). 


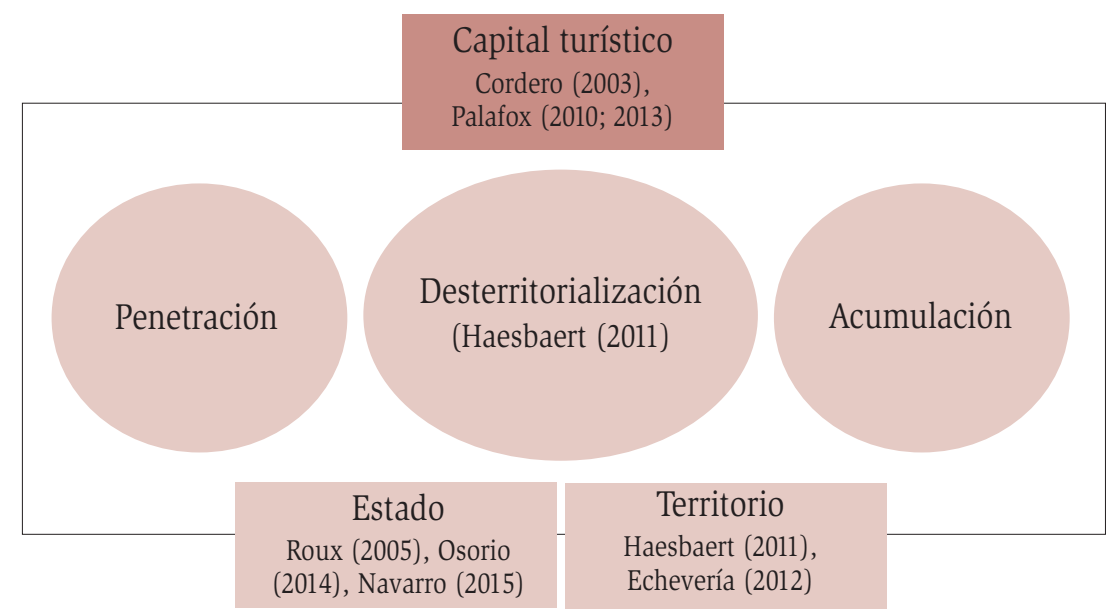

Fuente: Elaboración propia a partir de Vilchis Onofre, Zizumbo Villarreal, Monterroso Salvatierra, Arriaga Álvarez y Palafox Muñoz (2016) y Cruz Coria, Zizumbo Villarreal y Monterroso Salvatierra (2011).

\section{FiguRa 1: Esquema de propuesta teórico-metodológica}

La fase de penetración implica una serie de transformaciones superestructurales necesarias que debe acatar el Estado mexicano, a fin de permitir la reproducción del libre mercado en la fase globalizadora neoliberal capitalista. Estas transformaciones se establecen mediante nuevas políticas o la reestructuración de las ya existentes, la creación de instituciones y la formación de cuerpos administrativos. Tal como la inserción de una política turística, el cambio de uso y propiedad privada sobre la tierra, la flexibilización del trabajo, la depreciación de la moneda, la reducción del aparato estatal en los procesos productivos, la privatización de empresas paraestatales, entre otras, como parte de la negociación del Consenso de Washington con las políticas de corte neoliberal (Martínez Rangel y Soto Reyes, 2012). En esta fase se observa mayor participación del capital y el aparato estatal, pues el primero no puede establecer su voluntad sin la autorización del Estado, el cual es el único capaz de imponer intereses privados como intereses de la sociedad en general (Osorio, 2014) a través de la legitimación, dentro de las diversas estrategias de dominación (Navarro Trujillo, 2015; Roux, 2005). 
El proceso de desterritorialización (Haesbaert, 2011) se manifiesta como la aplicación de las políticas que van a permitir la acumulación del capital, definidas en la fase de penetración. En este sentido, en Bahía de Banderas fue necesaria la separación de los campesinos de sus tierras a lo largo de la línea del litoral, una vez que se permitió la propiedad individual de estas con la reforma al artículo 27 constitucional (Olivera Lozano, 2005; Monterroso Salvatierra y Zizumbo Villarreal, 2009; Calva, 2007). Este eje de análisis central significa dos cosas importantes: el despojo de las poblaciones rurales de sus territorios y el tránsito a una nueva dinámica económico-político-cultural en beneficio de unos cuantos junto a la desaparición de la organización social de tipo ejidal institucionalizada anteriormente. Aquí es posible identificar una mayor participación del Estado, pues este es el que ejecuta la acción de despojo de manera legal o ilegal para diversos fines. En el primer caso, justifica esta acción bajo el "recurso de utilidad pública” para el desarrollo de la actividad turística, prometiendo beneficios sociales a costa de la privatización y explotación del territorio por parte de capitales privados. Cabe mencionar que el territorio es considerado no solo un espacio físico sino también de construcción social, donde surge otro actor clave: las poblaciones locales afectadas (Haesbaert, 2011).

Finalmente, en la acumulación, tras el proceso de penetración de las políticas exógenas y la desterritorialización, es posible el establecimiento de los capitales privados en tierras de propiedad ejidal. En este caso, para desarrollar un modelo turístico hegemónico, donde su éxito se fundamenta en la creación de infraestructura a gran escala de alta calidad para satisfacer una demanda elitista nacional pero principalmente extranjera (Palafox Muñoz, Zizumbo Villarreal y Arriaga Álvarez, 2010; Palafox Muñoz, 2013). Esta fase deja ver, por un lado, el apoyo continuo por parte del Estado para la llegada y expansión de inversión del ramo de la industria turística que se beneficia con la adquisición de franjas costeras privilegiadas por sus condiciones geográficas para la venta de servicios turísticos, y, por otro, el despojo, desplazamiento e inserción al trabajo asalariado dentro del sector servicios; las condiciones precarias de vida a partir del cambio en sus modos de vida, crecimiento poblacional, migración, establecimiento de conjuntos habitacionales de interés social de mala calidad, carencia de servicios básicos, endeudamiento debido a la depreciación salarial, inestabilidad laboral, nulo aprovechamiento de los bienes naturales que antes 
les pertenecían y pérdidas de usos, costumbres y tradiciones a partir de ello (Fernández, 2011).

Como metodología de la investigación, se siguieron algunos pasos. Primero, la revisión documental de medios de información académico-científicos, periodísticos, bibliográficos, hemerográficos, documentos electrónicos, tesis, documentos oficiales, publicaciones periódicas, entre otros. Después se realizó una visita de campo al lugar de estudio, donde se aplicó una guía de observación y entrevistas a informantes clave, entre ellos principalmente ejidatarios residentes originarios del lugar, aunado al uso de la observación participante y no participante, diarios y notas de campo.

La experiencia de Bahía de Banderas en Nayarit expresa, en sus propias palabras, el proceso de transformación de la región, de ser un lugar de reproducción de vida, a un polo de desarrollo turístico para la reproducción de un modelo hegemónico en beneficio de un pacto Estado-corporaciones (Echeverría, 2012), a través del despojo entre los campesinos y su tierra. Aquí es importante no solo hablar del momento coyuntural de cambio sino también de las condiciones territoriales anteriores y posteriores, que permitan visualizar una serie de afectaciones particulares.

\section{Ubicación y características generales de Bahía de Banderas}

El municipio de Bahía de Banderas se encuentra localizado en el extremo suroeste del estado de Nayarit, entrante del océano Pacífico entre las costas de Nayarit y Jalisco y colindante con Puerto Vallarta. Su hidrografía cuenta con diversos ríos, como La Cucaracha, La Palapa, Galván, Las Truchas, Las Mesas, El Indio, La Peñita, Hustitán, La Quebrada, Charco Hondo, Calabazas, Las Ánimas, Carricitos, Bucerías y Ameca, así como la laguna de El Quelele. El río principal, Ameca, destaca por sus 1250 millones de metros cúbicos de escurrimiento que desembocan en las costas del Pacífico (César Dachary y Arnaiz Burne, 2006).

Colinda al norte con el municipio de Compostela y la localidad de Varas, al este con el estado de Jalisco y la sierra Madre del sur, al sur con el océano Pacífico y el estado de Jalisco y al oeste con el océano Pacífico. Todo ello como parte de la región Costa Sur. Al sur limita con su antecesor y principal destino turístico Puerto Vallarta en Jalisco. El acceso a esta región es a través de la 
carretera Núm. 200 y el aeropuerto internacional de Puerto Vallarta (figura 2) (César Dachary y Arnaiz Burne, 2006).

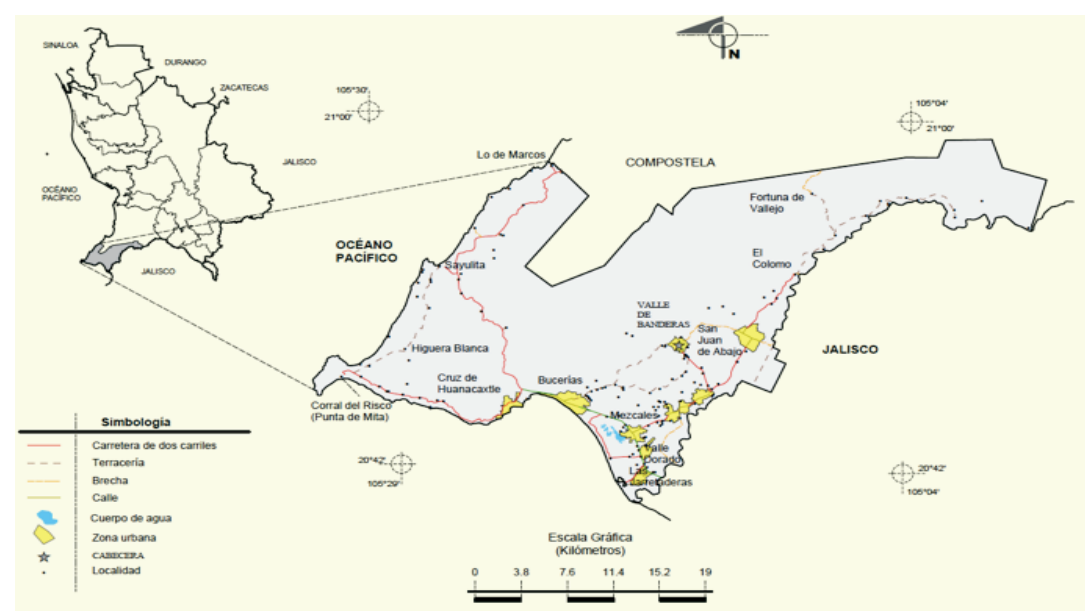

Fuente: Instituto Nacional de Estadística y Geografía (2009).

FiguRa 2. Mapa de ubicación geográfica de Bahía de Banderas

En cuanto a sus características físicas destaca una extensión territorial de $768 \mathrm{~km}^{2}$, que representan $2.8 \%$ de la superficie de todo el estado de Nayarit. A esta deben agregarse los $2.5 \mathrm{~km}^{2}$ de superficie del archipiélago de las Marietas, hecho que lo ubica en el decimotercer lugar de extensión territorial en todo el estado. En extensión litoral, donde se ha desarrollado gran parte de la oferta turística en esta región, posee un total de 68 kilómetros de costa y una parte elemental de montañas pertenecientes a la sierra Madre del sur, la cual es considerada como una importante reserva ecológica cuya antigüedad sobrepasa los 185 millones de años (López Guerrero, Chávez Dagostino y Moncada Cooley, 2001-2002).

Respecto al tema sociodemográfico, ha habido cambios importantes sobre todo con los procesos de transformación socioespacial que ha sufrido el territorio. La población del municipio de Bahía de Banderas era de 59808 habitantes en el año 2000, pero se ha incrementado en los últimos años, llegando a 124205 para 2010. Hay un predominio de población joven, por lo que se percibe la dualidad de las localidades cuyo desarrollo depende de un solo sector 
económico, el turismo (Secretaría de Desarrollo Social, 2010). Y puesto que se ha priorizado el desarrollo hacia esta región, es el municipio con mayor desarrollo turístico en todo el estado. Sin embargo, pese a la pujanza de esta actividad se observa que de la misma manera se han conformado conjuntos habitacionales de interés social de mala calidad, denotando la segregación a partir de los desarrollos tipo enclave.

La población económicamente activa es de 12 años en adelante en 54.7 \% , de la cual $98.2 \%$ se encuentra ocupada, de acuerdo con las cifras proporcionadas por el Censo de Población y Vivienda 2010 (Instituto Nacional de Estadística y Geografía, 2010). Las principales actividades económicas, teniendo en cuenta la ocupación, son el comercio en primer lugar, y le siguen el sector de la construcción y el de la prestación de servicios, dentro de los cuales sobresale el renglón turístico.

Otras actividades económicas en orden de importancia son las agropecuarias, la pesca y, por último, la manufacturera. Ha resultado, por sus características, una importante región para la producción agropecuaria, marítima y turística.

Las condiciones de vivienda de la población dentro del municipio se dividen en tres regiones. La primera se encuentra conformada por las localidades de la porción costera donde las viviendas están construidas con materiales de concreto, acero y ladrillo o block, zona donde se ubican los desarrollos turísticos más importantes, a su vez con asentamientos irregulares, y algunos servicios básicos insuficientes. Por otro lado, está la región centro, con viviendas en su mayoría de concreto, acero, ladrillo y block. Aquí el porcentaje de servicios básicos disminuye considerablemente con graves problemas de hacinamiento y compartimiento, en más de una vivienda, de los servicios sanitarios, construidos con estándares mínimos. Por último, en la región sierra, las viviendas se constituyen de materiales precarios o menos resistentes, por ejemplo madera y lámina, detectándose en ella las áreas con mayor marginación (Gobierno Municipal de Bahía de Banderas, 2014).

Respecto a la oferta de servicios turísticos, en alojamiento se cuenta con alrededor de 18742 cuartos de hotel (Secretaría de Turismo, 2016), y de acuerdo con las cifras de 2014, este destino es visitado por aproximadamente 2350000 personas al año (Gobierno Municipal de Bahía de Banderas, 2014). Entre las distintas actividades destacan las ecoturísticas, como el avistamiento de ballenas, 
Cuadro 1. Establecimientos de hospedaje registrados por municipio según tipo de alojamiento. Al 31 de diciembre de 2015

\begin{tabular}{|c|c|c|c|c|c|c|c|}
\hline Municipio & Total & Hoteles & Moteles & $\begin{array}{l}\text { Cabañas, } \\
\text { villas y } \\
\text { similares }\end{array}$ & $\begin{array}{l}\text { Campamentos } \\
\text { y albergues } \\
\text { recreativos }\end{array}$ & $\begin{array}{l}\text { Pensiones } \\
\text { y casas de } \\
\text { huéspedes }\end{array}$ & $\begin{array}{c}\text { Departamentos y } \\
\text { casas amuebla- } \\
\text { das con servicio } \\
\text { de hotelería }\end{array}$ \\
\hline Estado & 658 & 288 & 61 & 201 & 16 & 17 & 75 \\
\hline Acaponeta & 8 & 5 & 3 & 0 & 0 & 0 & 0 \\
\hline Ahuacatlán & 4 & 4 & 0 & 0 & 0 & 0 & 0 \\
\hline $\begin{array}{l}\text { Amatlán de } \\
\text { Cañas }\end{array}$ & 6 & 4 & 0 & 2 & 0 & 0 & 0 \\
\hline $\begin{array}{l}\text { Bahía de } \\
\text { Banderas }\end{array}$ & 202 & 79 & 0 & 44 & 6 & 7 & 66 \\
\hline Compostela & 225 & 65 & 2 & 140 & 6 & 3 & 9 \\
\hline Del Nayar & 3 & 3 & 0 & 0 & 0 & 0 & 0 \\
\hline $\begin{array}{l}\text { Ixtlán del } \\
\text { Río }\end{array}$ & 13 & 8 & 5 & 0 & 0 & 0 & 0 \\
\hline Jala & 3 & 2 & 0 & 0 & 0 & 1 & 0 \\
\hline Rosamorada & 3 & 2 & 1 & 0 & 0 & 0 & 0 \\
\hline Ruíz & 8 & 4 & 4 & 0 & 0 & 0 & 0 \\
\hline San Blas & 41 & 26 & 0 & 9 & 4 & 2 & 0 \\
\hline $\begin{array}{l}\text { San Pedro } \\
\text { Lagunillas }\end{array}$ & 3 & 3 & 0 & 0 & 0 & 0 & 0 \\
\hline $\begin{array}{l}\text { Santa María } \\
\text { del Oro }\end{array}$ & 6 & 1 & 1 & 3 & 0 & 1 & 0 \\
\hline $\begin{array}{l}\text { Santiago } \\
\text { Ixcuintla }\end{array}$ & 12 & 7 & 4 & 0 & 0 & 1 & 0 \\
\hline Tecuala & 17 & 13 & 4 & 0 & 0 & 0 & 0 \\
\hline Tepic & 90 & 54 & 33 & 2 & 0 & 1 & 0 \\
\hline Tuxpan & 8 & 7 & 0 & 0 & 0 & 1 & 0 \\
\hline Xalisco & 6 & 1 & 4 & 1 & 0 & 0 & 0 \\
\hline
\end{tabular}

Fuente: Secretaría de Turismo del Gobierno del Estado, Dirección de Planeación: Departamento de análisis, Estadísticas e información. Con base en INEGI. Dirección general de estadísticas económicas. Directorio Estadístico Nacional de Unidades Económicas (DENUE). www.INEGI.org. mx (2 de febrero de 2016).

tortugas marinas y aves, y el turismo de aventura, con tirolesa, recorridos en cuatrimoto, surf, cabalgatas, pesca deportiva, y algunas más (Andrade Romo y Martínez Lorenzo, 2012).

También existen algunas fiestas importantes, como el Festival de Bahía de Banderas, con un carácter deportivo y cultural; el 2 de febrero se celebra a 
la Señora del Rosario de Tintoque; el 24 de enero, a la Santísima Virgen de la Paz en la capilla de Bucerías; del 10 al 19 de marzo, a san José en el barrio del mismo nombre; y además se realizan las fiestas patronales de San Juan de Bajo, donde se celebra a san Juan Bautista, así como las del Porvenir, el 16 de octubre y 8 de diciembre. En aspectos más ancestrales, sobresalen las artesanías huichol y cora, la madera tallada, la joyería de plata, los artículos de cobre y barro para la cocina, y los muebles rústicos.

La gastronomía, por su parte, conserva algunos platillos típicos, como el soporrondongo, que consiste en un pequeño tamal frito elaborado con masa de elote que la población consume en la época de cosecha de maíz; pescado y camarón "embarazados", asados al carbón en una vara que los atraviesa; langosta cocinada en distintas modalidades; la almeja reina preparada en su concha, que es poco consumida debido a su escasez; y la comida tradicional mexicana.

El crecimiento de la industria inmobiliaria ha sido un factor destacable para la expansión turística en la franja costera nayarita. La construcción de hoteles necesitó de mano de obra, pero conforme más se requería, esta se abarataba. Esto afectó a la población trabajadora local, dándose un fenómeno migratorio que hasta la fecha se sigue presentando, pero por su característica fluctuante, no permite conocer indicadores reales sobre personal ocupado dentro de esta rama económica.

Así pues, el turismo constituye un importante factor económico para el estado de Nayarit, donde la región de Bahía de Banderas se ha impulsado de tal forma que, al día de hoy, es el principal polo de desarrollo turístico de la entidad. Una de las estrategias de promoción fue el establecimiento de su propia marca, con el nombre de Riviera Nayarit, que concentra como puntos turísticos más importantes Bucerías, Flamingos, La Cruz de Huanacaxtle, Costa Banderas, Sayulita-San Francisco, Punta Mita-Litibú y Nuevo Vallarta (A. Romo, entrevista personal, 6 de julio de 2016). En este sentido, se piensa que su desarrollo deviene de un proceso histórico que se basa en la participación de diversos actores: por un lado, el Estado y los inversionistas, y, por otro, las poblaciones rurales. Ambas partes se confrontan, en cuanto que el binomio Estado-inversores tiende a transformar el paisaje para la acumulación de capital contra la idea y aprovechamiento del territorio para la reproducción de la vida. 


\section{Conformación territorial hasta 1970: Bahía de Banderas y Nuevo Vallarta}

Las primeras transformaciones sobre la tierra se dieron en la región montañosa llamada El Valle -usada anteriormente para el autosustento de los pueblos-, para pasar a una explotación agroindustrial con las llamadas "plantaciones", destinadas solo al comercio de exportación y dar paso a la producción agrícola industrial, así como la minería en la sierra del Cuale. Algunas de estas plantaciones fueron abandonadas debido a la ruda, cruel y violenta explotación de los españoles hacia los indígenas, teniendo estos que huir hacia las montañas y sierras del noroeste. Los hispanos, al no soportar el clima de la costa, abandonaron la cosecha de cacao y cacahuate. Varias propiedades del Valle, durante esta época, pertenecían a órdenes religiosas y al clérigo, y otras más estaban en manos del Cura Real de Minas de San Sebastián Diego de Aguirre. Sin embargo, las tierras habían sido obtenidas de forma rapaz y representaban solo un artículo comercial para los conquistadores. Los hacendados continuaban en la ampliación de sus propiedades bajo dos condiciones en relación con los indígenas: mal trato y pagos miserables, lo cual produjo, en 1801, una rebelión (Munguía Fregoso, 1997).

Hasta 1859, el rancho perteneció a la nación, pero en 1857 Jesús Camarena, diputado del Congreso Constituyente, recibió más de 19000 hectáreas para explotación minera por concesión del presidente de la república Ignacio Comonfort. Un año después, cuando Benito Juárez asumió la presidencia, amplió las hectáreas dadas a Camarena hasta el mar, aumentándolas a 56 674, en nombre de promover la producción alimentaria vinculada con la minería.

En el último año del siglo xix el estadounidense Alfred W. Geist compró 90 \% de la compañía Unión en Cuale, posesionándose de tierras, minas y parte de las Peñas. De hecho, vendía los lotes de 12.5 x 25 metros a 2.50 pesos el metro cuadrado o en renta por 2 pesos anuales. Durante el mismo año, la nación creó la Ley de Terrenos Baldíos y de Colonización (1883-1893) para poblar las tierras sin ocupación. Por un lado, grandes cantidades de indígenas fueron desterrados para ser lanzados al mercado de las haciendas, y, por otro, la búsqueda de bienestar económico trajo migrantes a la zona costera, lo cual resultó también en beneficio con la mano de obra para las haciendas (Luna Jiménez, 1993). 
Con la nueva Constitución de 1917 los hacendados se empezaron a desintegrar, y con ello fueron perdiendo dominio sobre la tierra. Para este tiempo, no solo se dieron cambios en la tenencia del suelo, sino también en la redistribución espacial de la población, así como la transformación de los recursos naturales y la desaparición de ciertas prácticas productivas. Los campesinos poseedores de las tierras no contaban con los recursos suficientes para producir. Al no haber instituciones bancarias que les otorgaran créditos, los ejidatarios pedían préstamos a las casas comerciales de Vallarta, pasando a rendir cuentas a estas y ya no al hacendado, como anteriormente se hacía. La industria manufacturera se fue acentuando y cobró gran auge, trayendo consigo vías de comunicación; la industria del tabaco también sobresalió al monopolizarse bajo la Campaña Comercial las Peñas (Luna Jiménez, 1993).

Se desintegraron las haciendas capitalistas y surgieron los capitalistas industriales, teniendo a su servicio a los ejidatarios. Asimismo, fue instaurado un nuevo poder socioinstitucional, donde se facultó al Estado para su total intervención en el sistema económico y político del país. Estimuló el desarrollo y la industrialización por medio de la inversión pública, la creación de infraestructura, empresas paraestatales, transferencias de valor, subsidios, protección al mercado interno, entre otras cuestiones. Se convirtió en impulsor del crecimiento económico ante una burguesía nacional parcialmente débil (Trejo, 2012). Se vivía en el país una reconfiguración del territorio tanto en lo económico como en lo social, y gracias a la rica oferta de bienes naturales, fue posible el desarrollo de un sector secundario.

Es así que de 1934 a 1940 empezó a regir una economía mixta, donde el Estado nacional-populista permitió la acumulación a partir de la riqueza nacional privada y pública; profundizó la Reforma Agraria; invirtió en áreas sin interés para la iniciativa privada; expropió y nacionalizó empresas importantes, entre otras cosas, lo cual dio pie a una forma reguladora del Estado en la economía nacional.

El reparto agrario de 1934, al mando del presidente Lázaro Cárdenas, significó la entrega de lo que al pueblo le pertenecía: la tierra. A partir de ello, se conformaron los ejidos de la región: Jarretadera, Bucerías, Cruz de Huanacaxtle, Higuera Blanca, Sayulita, Peñita de Jaltemba, las Varas y El Capomo. Este hecho traería para el pueblo un periodo de gestión sobre sus tierras, actividades 
productivas y formas de vida. En conjunto, todos estos ejidos configuran hoy parte del municipio de Bahía de Banderas (A. Romo, entrevista personal, 6 de julio de 2016).

Entre las actividades predominantes, un tanto económicas y otras más de autosustento, predominaba la agricultura con la extracción del aceite de coco entre noviembre y mayo, para venderse principalmente al municipio de Compostela; empezó la plantación de plátano, portalimón, maíz, frijol, tabaco, mango, chile, cacahuate, calabaza, jamaica, ajonjolí y sorgo. En el caso del plátano, se exportaba en barco y se cargaba en el atracadero probablemente para ser vendido en Mazatlán o San Blas, pero las condiciones de terracería antes de 1966 dificultaban el traslado de la producción. En tiempo de lluvias era imposible, y en temporada de secas, los traslados se hacían hasta en dos días desde Compostela a Vallarta; el tabaco se llevaba en forma de pacas al centro de acopio de Vallarta, donde era comprado por familias adineradas. Se usaba dar dinero anticipado a los campesinos para iniciar la preparación de la tierra, luego estos lo pagaban con parte de la cosecha obtenida, y lo sobrante era su utilidad (G. Parra, entrevista personal, 27 de junio de 2016).

Otra actividad era la pesca, pues los recursos marítimos eran abundantes. Se extraía jaiba, camarón, pescado, chachalaca, tiburón, pajarito, almeja, ostión, guabinas, cuerda y caracol chino. Estos recursos podían ser obtenidos tanto de la costa como del río Ameca por medio de canoas de remo y vela. Los pobladores daban gran significado a los bienes naturales, pues solían proveerlos del alimento para vivir; bienes marítimos y terrestres eran considerados suyos y en libertad total de extraerlos. Aun cuando se comercializaba con los bienes pesqueros, estos iban destinados en mayor medida al autoconsumo. También se practicaba la caza y la ganadería, aunque la venta de ganado era mínima. Predominaban especies como la vaca, el venado y el cerdo.

La producción del campo, de acuerdo con los ejidatarios, era sólida, hasta cierto punto, en cuanto la existencia de la Compañía Nacional de Subsistencias Populares (Conasupo), porque compraba lo producido por los ejidatarios, pero al desaparecer empezaron algunos problemas, principalmente porque se pagaba un menor precio por la producción. El gobierno puso en marcha otro programa llamado Apoyos Directos al Campo (Procampo) para aliviar un poco esta situación, aunque después las condiciones empeoraron considerablemente, 
al grado de abandonar en gran medida la actividad agrícola (G. Fernández, entrevista personal, 30 de junio de 2016).

En cuanto organización política, cada ejido contaba con su propio comisariado y se mantenía comunicación entre todos, mediante la creación de asambleas para pedir apoyos y otras cosas. Sin embargo, la organización política a través de los ejidos presentaba algunos problemas con respecto al trabajo de la tierra: falta de autoridad, gestión y preocupación por los cultivos, teniendo los ejidatarios que unirse para mejorar esta situación. Incluso se llegó a buscar la desintegración de ejidos para ser anexados a otros por parte de sus integrantes, quizá para incrementar la extensión geográfica y poblacional de alguno en particular con cierto dominio en la zona (D. Dávalos, entrevista personal, 22 de junio de 2016).

El reparto de tierras atrajo importantes masas de población de lugares cercanos como Xalisco, San Sebastián, Mascota, Talpa, Huachinango, Tomatlán y Cabo Corrientes. La obtención de parcelas era tan accesible como anotarse en lista para recibir las tierras y convertirse en ejidatario, con la condición de dar una aportación, la cual era suficiente con solo otorgar una parte de las cosechas obtenidas del trabajo de la tierra. Esta fue la manera en la que, aun sin ser originarios del lugar, hubo propietarios con parcelas ubicadas mayoritariamente hacia las montañas, en la región llamada "el Valle", donde se localizan los poblados de Mezcales, San Juan de Abajo, Valle de Banderas, El Colomo, San José del Valle y San Vicente (G. Parra, entrevista personal, 27 de junio de 2016).

La forma de vida cultural, para entonces, estaba relacionada con la pesca, ganadería, agricultura y caza. Aunque durante los periodos de lluvia se reducían las labores del campo, quedando sin mucha actividad. De acuerdo con los entrevistados, se vivía tranquilamente, con poca gente y feliz, donde las personas solían reconocerse y saludarse entre sí. Había fiestas y tradiciones populares, como ferias o las peregrinaciones a la Virgen de Guadalupe -del 30 de noviembre al 12 de diciembre- con carros alegóricos y otras cosas. La gente prefería vivir más hacia el lado de la costa y no de la sierra, pues esto facilitaba la siembra del maíz y, en el caso del río Ameca, el aseo y la alimentación. De hecho, se consideraba una tradición ir de paseo en familia hacia al mar, esteros, ríos y lagunas dada la libertad de acceso para pescar, abasteciéndose de sus fuentes necesarias de vida gracias a las condiciones semivírgenes del lugar. También se trasladaban a Vallarta por medio de carretas o burros, canoas o 
incluso nadando. Se vivía bien y de manera tranquila, trabajando. A pesar de la migración proveniente de otras partes de la región, el medio considerado como virgen daba a toda la población una oferta muy variada de alimento, y de forma totalmente natural. Por ejemplo, la leche bronca obtenida de las vacas o comer pollo resultaba ser todo un ritual, desde cazarlo, matarlo, limpiarlo y cocinarlo (L. de Jesús, entrevista personal, 30 de junio de 2016).

Respecto a los roles sociales, los hombres en su mayoría se dedicaban al trabajo del campo, mientras las mujeres a la comida y los quehaceres del hogar, como planchar o lavar, además del cuidado de los hijos. Por las calles de los pueblos era común hacer torneos, bailes, jaripeos, carreras de distintos tipos; se jugaba béisbol, jineteo con caballos, alar las aves en los corrales, entre otras actividades.

El ambiente social estaba regido por la naturaleza, la cual ofrecía sus bienes a la población local para ser tomados de acuerdo con sus necesidades. Al ser la población poseedora de las tierras, no existía algún tipo de ambición como parte de la cultura local, por lo que el tiempo era dedicado a actividades de ocio, contemplación del paisaje, buceo, o a aquellas de autoconsumo -pesca, ganadería, caza, agricultura-, o bien, a socializar. Era común la solidaridad y participación de las personas en cualquier actividad. No existían las clases sociales ni los intereses de una clase en particular, sino una comunidad colectiva, donde todos eran iguales, con sus derechos de vida, recreación y reproducción (G. Fernández, entrevista personal, 30 de junio de 2016).

\section{El área de Nuevo Vallarta}

El lugar que hoy ocupan Nuevo Vallarta, Jarretadera, Mezcales y Mezcalitos parece haber sido una zona de influencia de un antiguo pueblo indígena llamado Apetlatuca, donde se tejen esteras o petates y canastas. Por encontrarse cerca de la desembocadura del río Ameca y los esteros de El Chino, se daba la producción de algodón y sal. Los encomenderos de este sitio fueron Alonso Castañeda y Pedro Ruiz de Haro alrededor de 1548. Para 1608, perteneció a Apetronila de Ávalos; en 1623, a Pedro Ávalos; en 1663, a Juan Rodríguez Gutiérrez, quien heredó a Petrona de Ovalle. Al enviudar, vendió la propiedad al presbítero Francisco de Amezquita, fundador del beatario de Jesús de Nazareno. En 1695, la propiedad pasó a las madres beatas de Jesús de Nazareno de Guadalajara, con el nombre de Tongoroque, Montegrande, Garrocha y Chino. 
La propiedad limitaba al norte con el pueblo de Valle de Banderas, hoy con Bucerías, y, al sur, abarcó hasta la desembocadura del río Ameca. El latifundio de las Madres Beatas de Jesús de Nazareno fue conocido como las Monjas o el Colexio Chiquito. ${ }^{1}$

Por la extensión de los esteros, la división del Valle por el río Ameca y la organización social de señoríos, probablemente el dominio sobre las salinas haya estado en manos de dos pueblos pequeños cercanos al mar, los cuales hacían sal en los esteros para proveerla en esta zona y parte de la provincia. Uno de ellos era Iztapa, que significa "salinas", y el otro Apetlatuca. La tierra era fértil para hacer cacao, sobre todo por la oferta de sal. Boca de Tomates, El Papayal, El Chino y la Laguna del Quelele, en Nayarit, son los principales cuerpos de agua salina. Esto se ha corroborado en una visita de inspección a Nuevo Vallarta en 1992 por la arqueóloga Gabriela Zepeda, quien detectó varios promontorios prehispánicos donde habían sido construidos los campos del Club de Golf. En su momento, estos vestigios pudieron ser aldeas dedicadas a la extracción, control y distribución de sal. ${ }^{2}$

Siempre dedicada a la ganadería, la propiedad de las monjas o Colexio tuvo varios dueños. En el siglo xviI se registra al licenciado Juan José Rubio de Monroy, presbítero de Compostela, y a don Francisco García de Alba. En 1791, se decía dueño de las Monjas don Manuel Villalaz, quien logró concentrar todas las tierras del Valle desde el mar, hasta el límite con el Real de San Sebastián y Mascota. La enorme propiedad dejó de llamarse las Monjas, para registrarse como El Colexio o Colesio. En 1871, la señora Jana Barragán, de Tepic, declaraba haber adquirido la hacienda Colesio en 1852, por herencia de su madre, doña Juana Villalaz. En ese mismo año fue vendida a Doroteo Peña y a su hijo Ignacio Peña. La propiedad fue dividida durante esta venta, quedando fuera de escritura los predios que iban desde la desembocadura del río Ameca hasta Punta Mita. El registro de escritura sigue mencionando a Tongoroque y El Chino, y aparecen por primera vez los nombres de La Jarretadera y Mezcalitos. El nuevo propietario fue Jesús Cárdenas, aunque posterior a esta fecha no aparece

${ }^{1}$ Legajo 65-vol. 261 - 22. Compostela, Valle de Banderas. Madres Beatas de Nuestra Señora de Guadalupe de Guadalajara. Archivo de Instrumentos Públicos de Guadalajara. Ramo Tierras y Aguas. 1695-1718.

2 Zepeda García-Moreno, 1992, Carta al Ing. Gerardo Tapia. 
escritura a su nombre ${ }^{3}$ (Cronista oficial de Bahía de Banderas, 2016; E. Gómez, entrevista personal, 4 de julio de 2016).

En 1895, en remate por adeudo a la administración de Rentas del Territorio de Tepic, aparecen los terrenos nombrados en conjunto Jarretadera con una extensión de cuatro sitios de ganado, aproximados con límites al oriente y sur con la hacienda del Colesio, al poniente con la playa y al norte con el rancho de San Juan de Abajo (El Tepiqueño, 27 de abril de 1895).

A finales del siglo xix, La Jarretadera, con una extensión de alrededor de 20 000 hectáreas, fue adquirida por José Sotero Gil. En 1934, la población de las rancherías del área El Corral Solo (hoy desaparecida), La Jarretadera, El Papayal (también desaparecida) y Mezcales prestaron sus servicios a la hacienda en calidad de acasillados. Su situación en época de lluvias era precaria. Sobrevivían consumiendo plátano sembrado en los márgenes del río Ameca por la compañía Montgomery. Durante el reparto agrario de 1936, Jarretadera fue dividida entre los ejidos de Jarretadera, Bucerías y Cruz de Huanacaxtle. Los intentos por la dotación de tierras en el ejido La Jarretadera comenzaron el 26 de junio de 1934 por los vecinos de El Corral Solo, La Jarretadera y El Papayal, a quienes se unieron unos días después los pobladores de Cruz de Huanacaxtle. En un inicio, la solicitud de tierras debió estar firmada por Vicente Chávez, J. Jesús Aguilar y Gerardo Salcedo, como presidente, secretario y tesorero del Comité Ejecutivo Local.

El 5 de diciembre de ese mismo año se realizó el Consenso General Agropecuario, el cual arrojó 149 habitantes, 40 jefes de familia y 55 individuos, aptos para recibir las tierras. En este censo se sumaron los habitantes de El Papayal y Corral Solo. Señalaron como principal propiedad a afectar la hacienda Jarretadera de José Sotero Gil, a la cual pertenecían las poblaciones mencionadas. Su extensión aproximada de 20000 hectáreas corría por el litoral desde la desembocadura del río Ameca hasta el desagüe del arroyo de Pontoque, en Punta Mita. El 30 de marzo de 1935, la Comisión Agraria Mixta del Estado de Nayarit resolvió dotar en forma provisional al ejido de La Jarretadera con 896 hectáreas de la manera siguiente: de la hacienda Jarretadera, 224 hectáreas de humedad, en la isla de Zaragoza o isla de Las Juntas. El $1^{\circ}$ de mayo de ese año se hizo el deslinde y

${ }^{3}$ El Colesio. Libro 1, Inscripción $1^{\text {a }}$, Registro Público de la propiedad de Mascota, Jal. El Colesio. Libro 1; Inscripción 11. Registro Público de la propiedad de Mascota, Jalisco. 
posesión, recibiendo los señores Leonardo Hernández, Gerardo Salcedo y Vicente Marcial como presidente, secretario y tesorero del Comisariado Ejidal.

La resolución presidencial se dio el 11 de noviembre de 1936, la cual modificó el fallo provisional de la Comisión Mixta Estatal. El ejido de La Jarretadera fue dotado de 1002 hectáreas, de las cuales 202 fueron de humedad, 52 de agostadero susceptibles de cultivo y 748 de agostadero y monte. Tal extensión fue tomada íntegramente de la hacienda Jarretadera, quedando fuera la isla de Las Juntas o de Zaragoza, perteneciente a la compañía Montgomery de Ixtapa, Jalisco $^{4}$ (Cronista oficial de Bahía de Banderas, 2016; E. Gómez, entrevista personal, 4 de julio de 2016).

\section{Bahía de Banderas en el marco de los cip: de 1970 a 1990}

Entre las décadas de los cincuenta y sesenta, las vías de comunicación y medios de transporte eran sumamente escasos para conectar las localidades de la región Costa Sur, lo cual generaba cierto aislamiento entre los poblados. En ese preciso momento, ocurrían dos fenómenos importantes: por un lado, el proyecto de la carretera 200 (1955-1964), que iría desde Tepic hasta Vallarta, uniendo también a este puerto con el municipio de Compostela; por otro lado, la construcción del aeropuerto internacional Gustavo Díaz Ordaz en Puerto Vallarta a finales de los sesenta, que por su cercanía permitiría el acceso a la región de Bahía de Banderas.

Los dos eventos anteriores, como parte del equipamiento de Puerto Vallarta para su conformación en destino de sol y playa, determinaron un momento coyuntural para la apertura comercial de la región sur de Nayarit con el fin de atraer inversión extranjera en cuanto a servicios turísticos y la disminución del aislamiento entre sus diferentes centros poblacionales cercanos a las costas.

El recibimiento de turistas se empezó a notar con la entrada de vuelos desde Guadalajara a través de la compañía Mexicana de Aviación a partir de 1954, creciendo competitivamente contra otros destinos como Acapulco, aunque no llegó a tener la fama mundial de este último. El despegue internacional del destino turístico, aunado a los numerosos atractivos naturales dentro del municipio, llevaron al incremento del flujo de turistas y motivaron su crecimiento.

${ }^{4}$ R. A. N. Expediente La Jarretadera. C.C. A. 23-14724; 25-14724. 
Esta situación mostró al turismo como motor de expansión del capital, por medio de la inversión en infraestructura turística: hoteles, aeropuertos, carreteras, restaurantes, centros de entretenimiento, entre otros (Palafox Muñoz, 2011), por lo cual el Estado dio prioridad a la entrada, crecimiento y enriquecimiento de grupos turísticos internacionales, por sobre las necesidades y el desarrollo local de los pueblos, ignorando los costos que implicaría esta transformación.

El aumento de visitantes extranjeros empezaba a ser visible, tanto así que muchos venían a comprar tierras, sobre todo aquellas colindantes a las costas debido al estado virgen de sus playas. De la mano, la construcción de hoteles y establecimientos turísticos también iba en ascenso (Martínez Hernández, 2009). Ambos antecedentes, tanto la carretera como el aeropuerto, vinieron a provocar un crecimiento de las relaciones económicas y comerciales de manera más dinámica, principalmente para las poblaciones cercanas al aeropuerto.

Una década más tarde, las políticas federales se encaminaron a la homogeneización de las condiciones económicas y sociales de diversas regiones costeras en México, bajo el programa de desarrollo pesquero La Marcha al Mar, y para el turismo (César Dachary y Arnaiz Burne, 2006), los "polos de desarrollo" a cargo de instituciones públicas, lo cual consistió en insertar una actividad prioritaria a modo de irradiar el dinamismo económico hacia otras regiones. De esta forma, se eligió la actividad turística por su capacidad de generar flujos de ganancias mediante el intercambio de divisas que, en relación con el desarrollo regional, resultaba ser la actividad óptima para lograr las metas establecidas.

Así, por decreto, se señalaron distintos puntos de interés turístico determinando los sitios propicios para la puesta en marcha de estos polos tipo enclave 0 megaproyectos, a través de la conformación del Fondo Nacional de Fomento al Turismo (Fonatur). Inicialmente, se promovieron Cancún en Quintana Roo, Ixtapa-Zihuatanejo en Guerrero, Los Cabos y Loreto en Baja California Sur, y Bahías de Huatulco en Oaxaca. Más tarde, Bahía de Banderas en Nayarit. Pero, a fin de garantizar su rentabilidad, el Estado asumió la responsabilidad de favorecer, en todos los aspectos, aquellas condiciones que hicieran posible su desarrollo, como generar infraestructura urbana, legalizar la expropiación de las tierras ejidales en su mayoría, capacitar a la fuerza de trabajo, construir algunos inmuebles hoteleros o, en su caso, apoyar el financiamiento de empresarios turísticos tanto nacionales como extranjeros (Inda y Santamaría Gómez, 2015; Dávila López, 2014). 
De hecho, la primera acción estatal emprendida fue la legalización de la tenencia del suelo a manera de propiedad individual. En segundo lugar, la modificación de los estatutos dentro de la Constitución mexicana para permitir los cambios de apropiación de las tierras principalmente en las costas mexicanas en favor de capitales privados. Con ambos hechos, el Fonatur se dio a la tarea de adquirir terrenos para vender posteriormente a inmobiliarias particulares. Esto pudo llevar a la inversión directa de capitales privados, de forma clara y al margen de las leyes.

Para 1970, Puerto Vallarta, por su parte, ya era considerado un destino turístico en el nivel internacional, gracias al desarrollo de infraestructura de alojamiento y otros servicios complementarios, aspectos en los que participaban, por un lado, el Estado y, por otro, el capital privado. Incluso dos años antes, en 1968, el puerto obtuvo la categoría de ciudad durante la gubernatura de Jalisco del licenciado Francisco Medina Ascencio, a fin de obtener financiamiento para las obras requeridas (Munguía Fregoso, 1994).

La intervención estatal sobre el espacio de Bahía de Banderas no se hizo esperar, por lo que, con base en la nueva Ley Federal de la Reforma Agraria, y por disposición oficial, se constituyó, el 10 de noviembre de 1970, el Fideicomiso de Bahía de Banderas (Fibba) para servir como gestor intermediario entre la política federal y del estado en las organizaciones de la ruralidad mexicana, conformada por ejidos y comunidades localizadas en los territorios expropiados por la federación, con un total de 5162 hectáreas, con el objetivo de impulsar la venta y promoción de terrenos para el desarrollo inmobiliario cerca del litoral. Derivado de esto, sus finalidades irían encaminadas primordialmente al desarrollo turístico-habitacional que rodeaba Bahía de Banderas (Secretaría del Patrimonio Nacional, 1970).

La expropiación por parte del Estado se dio a través de distintas políticas y la creación de esta institución fideicomisaria, para privar del espacio al productor ejidatario, por lo que resulta ser una forma que reviste dos procesos: apropiación privada y despojo del espacio común.

Este hecho conforma gran parte del inicio del proceso de modificación estructural de la región Costa Sur del estado de Nayarit. Casi al término del periodo presidencial del licenciado Gustavo Díaz Ordaz, aliado con el presidente Robert Nixon de Estados Unidos (Guzmán Mejía y Anaya Corona, 2011), se 
decretó "de utilidad pública el desarrollo habitacional y turístico en los terrenos que circundan la Bahía de Banderas, ubicados en las costas de los Estados de Nayarit y Jalisco y el mejoramiento de los centros de población [...] así como sus fuentes propias de vida” (Secretaría del Patrimonio Nacional, 1970, p. 5). Con esta declaratoria, se expropiaron 4136 hectáreas en 140 kilómetros del litoral nayarita pertenecientes al municipio de Compostela, y 1026 hectáreas del ejido de Puerto Vallarta. En Nayarit, los ejidos expropiados fueron Jarretadera (382 ha), Bucerías (440 ha), Higuera Blanca (1 083 ha), Cruz de Huanacaxtle (375 ha), Sayulita (544 ha), Las Varas (184 ha), Peñita de Jaltemba (799 ha) y El Capomo (329 ha) (Secretaría del Patrimonio Nacional, 1970).

Aunque los fideicomisarios habían conformado un Fondo Ejidal en 1972, la promoción a cargo del creado Fibba marcó el inicio de un proceso de expansión de inversiones e infraestructura turística, que incluyó el desarrollo del fraccionamiento Nuevo Vallarta, el cual, junto con la zona costera aledaña, es destino de grandes capitales, así como de visitantes nacionales y extranjeros.

Este radio de acción trajo un efecto directo a los programas agrícolas, ganaderos, pesqueros, industriales, educativos y de vivienda popular de 60000 hectáreas, provocando inconformidad en los ejidatarios. Empezaba una serie de conflictos internos derivada de problemáticas ocasionadas entre estos, debido a los despojos, ventas y construcciones turísticas, ya que por más de diez años trataron de regularizar, sin éxito, las tierras (Martínez Hernández, 2009).

Aunado a lo anterior, el incremento del valor de las tierras provocó una demanda de visitantes y una valorización de los bienes naturales. Con ello, el Estado aprovechó para justificar su apropiación, donde la reconfiguración del territorio con el cambio de uso de suelo habitacional y turístico ha resultado un factor clave para la demanda de grandes compañías (Cruz González, 2015, p. 5). Con la creación del Fideicomiso, el Estado constituyó una estrategia que permitió la penetración del capital turístico, para la dominación de los espacios de producción tradicional y el control sobre la venta de las tierras ejidales (García Rivera, 1986).

Entre 1975 y 1984 se dio un incremento sin precedentes de la oferta de alojamiento en grandes y modernas instalaciones hoteleras y de unidades de tiempo compartido y completo, sumado a la construcción de nuevos equipamientos, como la marina y los campos de golf. A partir de 1985, el crecimiento acelerado 
de la demanda, como resultado de la edificación de grandes hoteles y unidades de tiempo compartido, impulsó la expansión urbano-turística en Puerto Vallarta con una elevada densificación. Bahía de Banderas, por su parte, también se vio afectada con nuevos productos turísticos bajo el modelo de alta densidad, empezando a modificar las tendencias de crecimiento de la zona con los fraccionamientos Flamingos y Nuevo Vallarta.

En 1988, a petición de grupos representativos, quienes se consideraban marginados por las autoridades municipales de Compostela, el congreso del estado realizó un amplio proceso de consulta con las comunidades, el cual fructificó al año siguiente con la decisión de crear el municipio de Bahía de Banderas mediante decreto número 7261 expedido en diciembre de 1989 (César Arnaiz, 2007).

Al mismo tiempo que Jalisco buscaba el desarrollo de los pueblos colindantes a Vallarta, Nayarit inquiría en posicionar la región Costa Sur. Por ello, se pensó en una estrategia para fortalecer y cimentar su fama como lugar de esparcimiento y diversión. Fue así que se impulsó la marca Riviera Nayarit (A. Romo, entrevista personal, 6 de julio de 2016). Entre sus principales playas se encuentran Lo de Marcos, San Francisco o San Pancho, Sayulita, Punta de MitaLitibú, Nuevo Vallarta, Costa Banderas, Cruz de Huanacaxtle y Bucerías.

En 1995 comenzó a limitarse la expansión de capitales turísticos y a disminuir la demanda de Puerto Vallarta como destino internacional, lo cual consolida la tendencia de crecimiento hacia la zona de Punta Mita con la construcción de nuevos espacios de alojamiento y productos de elevada calidad, por ejemplo Litibú y Costa Banderas (Periódico Oficial. Órgano del Gobierno del Estado de Nayarit, 2005). Una de las acciones políticas para impulsar el nuevo municipio fue el mejoramiento de los principales poblados con servicios de drenaje, luz y agua entubada. Diversos poblados fueron afectados de una manera singular (véase cuadro 2).

La industria, por ser un pilar económico importante de la región, también se vio intervenida con la planeación de una planta de cal hidratada en el ejido de Higuera Blanca, la cual se echó a andar solo en el momento de la inauguración; una planta trituradora de pétreos y una fábrica de productos premezclados de concreto en el poblado El Monteón, aunque a pesar de la inversión no se llegó a explotar; finalmente, una fábrica de tabique recocido, celosías y ladrillo en el poblado Lo de Marcos, misma que funcionó medianamente. 
Cuadro 2. Poblados y afectaciones particulares con el boom de la actividad turística en Bahía de Banderas

\begin{tabular}{|c|c|}
\hline Poblado & ACCIONES LLEVADAS A CABO \\
\hline $\begin{array}{l}\text { Rinc } \\
\text { Guay }\end{array}$ & $\begin{array}{l}\text { Se propuso como el primer fraccionamiento turístico } \\
\text { habitacional con proyecciones en el corto y mediano plazo, } \\
\text { con una inversión de } 276 \text { millones de pesos. }\end{array}$ \\
\hline $\begin{array}{l}\text { Peñita de } \\
\text { Jaltemba }\end{array}$ & $\begin{array}{l}\text { Quedó como principal distribuidor comercial, y como el lugar } \\
\text { sede para instalar los cuerpos administrativos del FIBBA. }\end{array}$ \\
\hline Jarretadera & $\begin{array}{l}\text { Al lado de este poblado, se constituyó el desarrollo turístico } \\
\text { llamado "Fraccionamiento Náutico Residencial Nuevo } \\
\text { Vallarta", pensado en la atracción de turismo de alto nivel } \\
\text { económico nacional y extranjero. Dentro de este, se construyó } \\
\text { particularmente un campo de golf profesional, el cual sería } \\
\text { considerado como una parte exclusiva del fraccionamiento. }\end{array}$ \\
\hline Bucerías & $\begin{array}{l}\text { Sería sede del Hotel Ejidal, que en sus inicios fue } \\
\text { administrado por los propios ejidatarios. }\end{array}$ \\
\hline $\begin{array}{l}\text { San } \\
\text { Francisco }\end{array}$ & $\begin{array}{l}\text { Albergaría el Museo del Mar, la escuela Técnica del Tercer } \\
\text { Mundo para alojar estudiantes de toda Latinoamérica y una } \\
\text { clínica del Seguro Social como hospital regional, que en su } \\
\text { momento contó con la tecnología más avanzada. }\end{array}$ \\
\hline $\begin{array}{l}\text { Punta de } \\
\text { Mita }\end{array}$ & $\begin{array}{l}\text { Se proyectó un fraccionamiento turístico ejidal y un conjunto } \\
\text { habitacional que serviría para brindar servicios a un turismo } \\
\text { en mayor medida nacional, de ingresos medios, pero que no } \\
\text { se llevó a cabo. }\end{array}$ \\
\hline
\end{tabular}

Fuente: Elaboración propia Elaboración propia a partir de Real Carranza, Olivarría Zepeda y Pacheco (2010).

Las pequeñas fábricas que permanecieron más tiempo en operación fueron una planta de muebles en el poblado de Cruz de Huanacaxtle y una empacadora de frutas y legumbres en Peñita de Jaltemba. Gran parte de estas industrias se pensaron rentables y adecuadas para satisfacer ciertas demandas generadas por las poblaciones, como la construcción de hoteles, restaurantes, centros comerciales, entre otros, lo que evitaría que se originara una dependencia de insumos primarios de construcción con otras regiones. Al mismo tiempo permitirían una capacidad de manejo y administración por parte de los pobladores. 
Uno de los bemoles fue pensar que el turismo resultaba ser la única oportunidad de desarrollo para los pueblos de Bahía de Banderas, porque en el sentido de encaminar todos los esfuerzos hacia la actividad turística, se hacían a un lado los aspectos de tipo cultural -usos y costumbres-, económico y político de los pobladores. Este hecho permitió al Fideicomiso incurrir en graves errores de planeación con la puesta en marcha de diversos proyectos, lo que provocó importantes fracasos y efectos sociales preocupantes desde entonces.

Algunos ejemplos de lo anterior son Rincón de Guayabitos, "tan mal planeado y sin tener la más mínima idea sobre los aspectos urbanísticos elementales que ninguna cadena hotelera se arriesga a instalarse" (Uno más Uno, México, 8 de octubre de 1981), situación que congeló a este lugar por más de una década. 0 el Hotel Ejidal en Bucerías, el cual fue cerrado por un largo tiempo y reabierto por la iniciativa privada a principios de los ochenta, porque "los ejidatarios no tienen idea del costo del hotel cerrado desde 1976 [...] construido por el Fondo Nacional de Fomento Ejidal (Fonafe), organismo desaparecido en 1975 [...], fue mal planeado, resultó incosteable y se convirtió en una piedra caliente para el estado no redundando en beneficios para el pueblo" (El Día, 1981; El Informador, 1977).

Por lo tanto, puede decirse que la urbanización de los poblados -que consistió en apoyos a lo social, agropecuario y turismo: recursos para la ganadería, creación de empleos, plazas centrales y banquetas, instalación de servicios básicos (agua, luz y gas), desarrollo de la pesca, otorgamiento de tractores y semillas mejoradas, cursos de alimentos y bebidas, capacitación y creación del primer hotel ejidal en Bucerías (César Arnaiz, 2005)- se basó en una planeación a corto plazo, sin considerar el crecimiento poblacional y urbano que el mismo desarrollo turístico generaría. El incremento demográfico y urbano fue significativo en corto tiempo, pasando de 36000 a 184000 habitantes para el año 2000 (Marín Guardado, 2009). Diversos problemas sociales también fueron notorios, como los casos de despojo, ya que con la creación del proyecto Náutico Residencial de Nuevo Vallarta se desalojó a la población que ahí habitaba, provocando el desempleo de jefes de familia que se dedicaban principalmente a la pesca (Novedades, 1979). 


\section{Costa Banderas bajo la política de internacionalización del turismo: de 1990 a 2005}

A partir de los años noventa, el crecimiento turístico se visualiza en dos periodos distintos, donde el estado fomenta el desarrollo de la costa de Bahía de Banderas con el producto turístico de Punta Mita. El primer periodo se considera de 1987 a 1993, con mayor interés en la región, el segundo, a partir de 1993, sobre la base de optimizar el uso de recursos en los municipios, a través de la descentralización de organismos instituidos para el fomento y desarrollo del turismo, teniendo en cuenta las zonas turísticas donde se apoyarían estos dos momentos de transformación.

Entre los organismos descentralizados se encuentra el Fideicomiso de Bahía de Banderas que, manejado por la federación, pasa a cargo del estado de Nayarit; otro caso importante fue la Secretaría Federal de Turismo, la cual fue extendida hacia representaciones estatales con el argumento de que esta acción permitiría a los gobiernos tanto estatales como municipales una pronta incorporación al proceso de modernización.

Así pues, las acciones políticas iban encaminadas a la promoción de nuevas inversiones a través del aprovechamiento de recursos y la búsqueda por consolidar aquellos enclaves ya establecidos. Fundamentalmente Nuevo Vallarta, ubicado dentro de los límites territoriales de Bahía de Banderas; Guayabitos, en el municipio de Compostela, y Puerto San Blas, en el municipio de San Blas. Es importante mencionar que, de los tres enclaves anteriores, existió un particular interés por Nuevo Vallarta y su costa cercana por cuatro aspectos esenciales: albergar la mayor concentración de servicios hoteleros de la más alta calidad en manos de las cadenas hoteleras extranjeras, resultar ser la alternativa más viable para alcanzar el desarrollo regional, dinamizar la economía del Estado y posicionar a Nayarit como destino de clase mundial (Real Carranza, Olivarría Zepeda y Pacheco, 2010).

Las acciones relacionadas con la actividad turística emprendidas por el Estado mexicano a través de los gobiernos estatales y municipales en esta y otras regiones cuya geografía coincide han sido pensadas desde las dinámicas de modelos ya existentes en otros países, principalmente de los desarrollados. En México, hoy es posible denunciar, sin lugar a duda, el predominio de un modelo turístico desde la década de los cincuenta, pero que hasta los setenta viene 
a ser nombrado y reconocido como tal: el turismo de "sol y playa", donde la participación de grandes cadenas trasnacionales de servicios es considerada como indispensable para el desarrollo de un turismo de "calidad", competitivo e internacional.

A este respecto, el Fonatur (2006b) publicó que el cIP Nayarit corresponde a una nueva generación de sus proyectos para localizarse en el corredor turístico Bahía de Banderas-Compostela-San Blas. Su primera etapa dio inicio en los predios de Litibú -desarrollo dirigido a un turismo de alto gasto y exclusividad en los segmentos de sol y playa, campos de golf, cultura y vivienda vacacional, asociado con los mercados nacionales e internacionales-, con el propósito de liberar el territorio para conformar el cIP, donde el gobierno federal procedió al desalojo de tierras y viviendas de la población local (J. Quintana, entrevista personal, 6 de julio de 2016).

Sin embargo, las condiciones sociales, particularmente políticas, económicas y culturales de México, son cuestionadas como aptas para continuar con la implementación de la actividad turística en este contexto, pues demanda diversas transformaciones territoriales. Esto ha originado una serie de afectaciones ambientales negativas. Por un lado, las de tipo social, como migración; saturación de espacios; aumento de subempleos y empleos precarios; déficit en vivienda y servicios; dependencia económica a una sola actividad; despojo; desplazamiento de espacios dedicados a la agricultura, pesca y ganadería; reubicación de las poblaciones originarias y ruptura de patrones socioculturales; crecimiento de una cultura de valores; encarecimiento de vida, lo cual provoca desigualdades en los sectores sociales, etc.

Por otro lado, las de tipo físico, por ejemplo contaminación de los océanos, ríos, cuencas, entre otras fuentes fluviales; desaparición de ecosistemas marinos: esteros, manglares y humedales, que a su vez provoca la vulnerabilidad ante fenómenos naturales mayores (ciclones, huracanes, tormentas tropicales o tsunamis); pérdida de la biodiversidad tanto terrestre como marina; degradación del suelo; urbanización del paisaje; alto consumo de recursos energéticos (energía, gas, luz, agua); erosión de playas naturales; generación de residuos, y algunas más (Fernández, 2011).

Así, dentro del marco jurídico permisible que ofrece la reforma de descentralización de funciones y transferencia de poder al ámbito estatal y municipal, 
junto a las políticas neoliberales, el estado de Nayarit reubicó en 1990 a un poblado pesquero, asentado desde 1942 en un espacio de singular belleza, el cual contaba con 479 habitantes en 101 viviendas. Este hecho permitió el desarrollo del megaproyecto turístico Costa Banderas, con una longitud de 21 kilómetros. Dentro del perímetro se desarrollarían cinco grandes proyectos para la captación de un turismo de altos ingresos, con la promesa de contribuir a detonar el desarrollo turístico regional de Nayarit, entre ellos Nuevo Vallarta. En lo económico, la ampliación de la oferta hotelera significaría aumentar las capacidades competitivas frente a otros destinos de reconocido prestigio del país, posibilitando la afluencia turística y con ello redituar una mayor entrada de divisas. En lo social, la generación de 18000 empleos directos que beneficiarían a 1200 campesinos de los núcleos de Emiliano Zapata, Higuera Blanca y Corral de Risco (El Tiempo de Bahía de Banderas, 13 de agosto de 1991).

A pesar de las buenas intenciones, debido a una negociación realizada entre inversionistas y pobladores a principios de los años noventa y cuya duración aproximada fue de tres años, se observaron disputas entre los propios pobladores, intervención y abuso por parte de la autoridad estatal en detrimento de estos, así como irregularidades jurídicas y legales para finalmente reubicarlos. Durante los tres años que duró el proceso de convencimiento, personas de otras localidades migraron hacia el poblado de Corral de Risco, para aprovechar los beneficios anunciados por el gobierno. Esto trajo consigo una fragmentación de la población total en dos grupos: por un lado, personas de edad avanzada en oposición y, por otro, los convencidos, en su mayoría gente recién llegada al lugar.

En el contexto de un turismo elitista desde el cual se planteó el enclave turístico Costa Banderas, ${ }^{5}$ el poblado formado ex profeso se ha convertido en una especie de espacio habitacional exclusivo para vacacionar por aquellos turistas o visitantes que pueden realizar gastos por arriba de la media nacional. ${ }^{6}$ La infraestructura de alta calidad de alojamiento y servicios complementarios demanda una recuperación económica que no sería posible sin el aumento del

${ }^{5}$ Los proyectos que conforman este desarrollo turístico son Proyecto Hidden Paradise, Desarrollo Costa Banderas, Desarrollo Punta de Mita, Proyecto Playa Estates y Proyecto Los Veneros. Estos son financiados por capitales nacionales, extranjeros o coinversiones entre ambos (Ochoa Z. 1995-96-97 y 98, II, III, IV y V Informes de Gobierno, Sria. de Turismo del Estado de Nayarit).

${ }^{6} \mathrm{El}$ promedio de gasto turístico por hogar en viajes con pernocta es de 5610 pesos, donde la estancia promedio es de cuatro días y cuatro noches, lo que da un gasto diario de 1122 pesos (Secretaría de Turismo, 2013). 
costo de los insumos, obligando a los antiguos pobladores de Corral de Risco a vender sus casas, aun cuando estas fueron construidas para ellos.

\section{Crecimiento inmobiliario: el reconocimiento de una marca turística, de 2005 a la fecha}

La proyección de Bahía de Banderas como destino turístico internacional dirigido a un sector de turismo de calidad y requería del acondicionamiento y construcción de servicios especializados. En particular, el crecimiento inmobiliario en la región se empezó a notar de manera importante a partir de la década de los noventa. De 1992 a 1997 se tuvo un incremento anual promedio de 12.8 \%, es decir, 252.2 cuartos al año, lo cual significaba la construcción de dos cuartos cada tres días dentro del periodo señalado. Más tarde, de 1997 a 2000, el número de unidades rentables aumentó en $60 \%$. Este crecimiento se centró en los desarrollos turísticos localizados fundamentalmente en Nuevo Vallarta y el corredor Cruz de Huanacaxtle-Punta Mita.

Para el año 2000, se alcanzaron 5390 unidades de alojamiento distribuidas en 94 establecimientos, entre hoteles de cinco estrellas y condominios de tiempo compartido. Se estima que están construidos 18742 cuartos de hotel, al 2015, en 202 unidades de hospedaje (INEGI, 2016), y 808 unidades de condominios, de los cuales aproximadamente $80 \%$ se ubica dentro del Fraccionamiento Náutico de Nuevo Vallarta.

Aunado a lo anterior, existe un número no cuantificado de segundas casas, cuyas propiedades pertenecen tanto a nacionales como extranjeros que invierten en la zona, mediante una serie de fideicomisos. De hecho, la iniciativa privada programó una inversión total de 1486.5 millones de dólares en Bahía de Banderas, en un periodo que va más allá de 2005 (Cortizo Álvarez, Trejo Gómez, Andrade Romo, Alonso González y Chávez Dagostino, 2012).

Entonces, en la búsqueda de posicionar a la región Costa Sur de Nayarit como destino turístico de competencia internacional y romper con la tradición de Puerto Vallarta, se promovió la marca distintiva de La Riviera Nayarita a partir de 2005. Esta propuesta nace con el Proyecto de la Escalera Náutica de la 
Región del Mar de Cortés, impulsado por el Fonatur, ${ }^{7}$ aunque solo consideraba los estados de Baja California Norte, Sonora y Sinaloa.

Sin embargo, en noviembre de 2002, mediante la firma del Convenio de Coordinación celebrado por el Fonatur, junto con el gobierno del estado de Nayarit y los gobiernos municipales de San Blas, Compostela y Bahía de Banderas, la extensión territorial nayarita fue incorporada al Proyecto Escalera Náutica del Mar de Cortés. Tal convenio consideraba tres escaleras náuticas, la gestión para modernizar la infraestructura carretera y la integración de una red aeroportuaria de apoyo. En 2008 se agregaron los municipios de Ixtlán del Río y Jala (Gobierno federal, 2016; Enciso, 2005; Fonatur, 2006a).

En virtud de los convenios firmados entre el Fonatur, los municipios y el gobierno estatal, nacieron una serie de acciones tendientes a propiciar el desarrollo del nuevo proyecto con el que se buscaría el posicionamiento de Nayarit en un ámbito internacional. Para ello se planteó la construcción de 30 nuevos hoteles, cuatro campos de golf, dos marinas náuticas y un aeropuerto que cubriría las necesidades del corredor turístico, entre los municipios de San Blas y Bahía de Banderas a lo largo de 175 kilómetros de playa.

Parte de los fundamentos para dar pie a la realización del megaproyecto se señalaron en un comunicado por el gobernador en turno, donde se mencionan los beneficios que traería el ambicioso plan, entre ellos, la generación de empleos y como alternativa de desarrollo regional con el aprovechamiento de los bienes naturales con los cuales cuenta la entidad; todo esto garantizado con la marca de La Riviera Nayarita y promovido en el plano internacional.

La urbanización de algunos sitios como Nuevo Vallarta, Flamingos, Punta Mita y Litibú se ha dirigido a la existencia de una hotelería moderna y de alta categoría, constituyendo el núcleo más importante de la actividad turística en Nayarit. Se construyeron dos nuevos campos de golf en Punta Mita -uno de

${ }^{7}$ En 1998, el Fonatur retoma el propósito de impulsar un desarrollo náutico turístico para la región del Mar de Cortés, presentando el Proyecto Mar de Cortés al Comité Técnico de Distribución de Fondos del Fonatur. Un proyecto de carácter regional para brindar una oferta integral de infraestructura y servicios de apoyo náutico, carretero y aéreo, mediante la integración por etapas de 20 puertos de abrigo y paradores náuticos, el desarrollo de un puente terrestre para el traslado de embarcaciones del océano Pacífico al Mar de Cortés, el mejoramiento de cinco rutas de acceso desde la zona fronteriza para embarcaciones remolcables, la integración de una red aeroportuaria de apoyo y de un sistema de abastecimiento de combustibles, así como acciones para facilitar la internación de turistas y equipos náuticos (Gobierno federal, 2016; Enciso, 2005; Fonatur, 2006a). 
ellos en el fraccionamiento Flamingos-, se reactivó la Marina de Nuevo Vallarta y se construyó una marina en la Cruz de Huanacaxtle, que en conjunto forman parte de la oferta de la marca con la que sería conocido Nayarit en el nivel internacional.

Por otro lado se encuentra el Megaproyecto Ecológico Costa de Banderas, que comprende una superficie de 1056 hectáreas, proyectado para cuatro 0 cinco campos de golf, marina para lanchas deportivas y pesca, aeropuerto privado y hoteles de gran turismo con las firmas trasnacionales Four Seasons, Princess, Rockefeller Resort, Ritz Carlton y Quinta Real, todo ello en un periodo de diez años.

La apuesta por estos megadesarrollos tiene que ver con una respuesta positiva por parte de visitantes extranjeros en la compra de condominios de tiempo compartido y completo. Es decir, que el mercado de bienes raíces en este lugar ha tenido una notable presencia y un alza extraordinaria, lo cual se ha visto como una estrategia para posicionar a la región de Bahía de Banderas dentro de los destinos turísticos más importantes en el mundo.

El municipio de Bahía de Banderas podría ser reconocido y preferido por el segmento de mercado de negocios, gracias a la competitividad que le dan los atractivos naturales y las facilidades de hospedaje. Asimismo, ha gozado de la economía externa del destino colindante Puerto Vallarta, su posicionamiento como destino turístico internacional y las vías de acceso, factores que han beneficiado distintos puntos turísticos en el plano nacional e internacional (Cortizo Álvarez et al., 2012).

A pesar de algunos vacíos en el esfuerzo cronológico construido de las acciones emprendidas por el gobierno estatal para el desarrollo del cIP, ha sido posible detectar el surgimiento de problemas relacionados con la compra de grandes zonas de tierras mayormente ejidales a precios irrisorios, el despojo de tierras a aquellos que se negaron a vender y al mismo tiempo una venta ilegal de terrenos, la privatización de estos por instancias federales e inversionistas privados, la presencia de abuso e influencia de poder y autoridad por los órdenes estatal y municipal, el deterioro del ambiente socionatural, entre muchos otros eventos, a favor de intereses particulares para la acumulación de capital. 


\section{Consideraciones finales}

La historia de la conformación territorial en la región de Bahía de Banderas deja ver los siguiente: concesión de tierras a grupos privados, reubicación poblacional, impactos ambientales y enriquecimiento individual, todo con la práctica continua de despojo. Primero, a la llegada de los españoles hasta el periodo del presidente Lázaro Cárdenas, quien fue el máximo representante de un lapso caracterizado por permitir la gestión autónoma de la población sobre la tierra. Aunque desde la colonización ya pueden identificarse claramente prácticas de colonización de los bienes, por parte del clero, terratenientes y, más tarde, estadounidenses; el mal trato y la explotación de los indígenas en el mercado de las haciendas, lo cual derivó en diversas rebeliones campesinas; así como la creación de políticas para la apropiación de territorios sin ocupación.

Otra cuestión importante es que, previo a la actividad turística, se llevaban a cabo otras formas extractivistas del capital: la minería y la producción alimentaria vinculada con esta. Industrias como la manufactura y la venta de tabaco también crecieron, por lo que tuvieron que crearse caminos y mayores servicios de urbanización, pues el crecimiento y apertura de nuevas actividades productivas provocó un efecto migratorio. Estos procesos llevarían a la desaparición de las haciendas capitalistas para dar lugar a los capitalistas industriales, quienes dominaron tanto la tierra como a los campesinos.

La tendencia ascendente del desplazamiento de personas, más tarde representada con el fenómeno del turismo, vino a establecer un nuevo uso de la tierra sobre todo para las zonas geográficas limítrofes al mar. Hoy en día, el turismo predomina sobre las actividades primarias y secundarias, las cuales han disminuido considerablemente y otras al punto de desaparecer en algunas áreas específicas. En parte, esto se debe a que los esfuerzos públicos han priorizado este nuevo mercado internacional a través del despojo y la privatización del espacio, aunado a la exclusión y segregación de los campesinos.

El despojo, ya sea de manera violenta o legal con la expropiación justificada para el desarrollo turístico, o, en otras palabras, la desterritorialización, ha sido y sigue siendo una dinámica fundamental para continuar con el proceso de acumulación y reproducción de la sociedad capitalista, en sus diversas formas extractivistas, como el turismo, que benefician a sectores sociales reducidos. Sin esta práctica, no podrían penetrar los capitales mundiales en las zonas 
geográficas de su interés. Por ello resultan indispensables estrategias de dominación para legitimar estas acciones, que solo el poder público estatal puede imponer. Sin embargo, en comparación con las formas violentas de despojo en la Colonia, las formas actuales son más sutiles mediante disciplina y normalización, gestión de la gobernabilidad, consenso o legalidad institucional como estrategias (Navarro Trujillo, 2015) para persuadir a las poblaciones desterradas y evitar con ello conflictos mayores. Los discursos de progreso, desarrollo y modernización en cuanto ideologías hegemónicas que prometen beneficios justos e igualitarios para los pueblos son interiorizados por estos, cuando en realidad el objetivo es instaurar un sistema mundial como forma de vida, donde se confrontan dos grupos de actores sociales: el binomio Estado-capital para beneficio económico privado a costa de la degradación socioespacial de vida de los pueblos rurales.

\section{Fuentes consultadas}

Andrade Romo, E. y Martínez Lorenzo, L. (2012). Diversidad. En F. J. Núñez Cornú y F. Rodríguez Gutiérrez, Gestión integrada de paisajes litorales. Hacia una metodología comparativa. Caso Asturias, España, y Bahía de Banderas, México (pp. 6-24). México: Plaza y Valdés Editores.

Calva, J. L. (2007). Políticas de desarrollo regional (colección Agenda para el Desarrollo, vol. 13). México: Universidad Nacional Autónoma de México/ Miguel Ángel Porrúa/Cámara de Diputados.

César Arnaiz, F. (2005). Ciudades turísticas: desarrollo e imaginarios Careyes y Nuevo Vallarta (Tesis de maestría en Desarrollo Sustentable y Turismo). Guadalajara: Universidad de Guadalajara, Centro Universitario de la Costa.

César Arnaiz, F. (2007). Ciudades turísticas: desarrollo e imaginarios Careyes y Nuevo Vallarta. México: Universidad de Guadalajara.

César Dachary, A. A. y Arnaiz Burne, S. M. (2006). Bahía de Banderas a futuro: construyendo el porvenir 2000-2025. Xalisco, Nayarit: Universidad de Guadalajara, Centro Universitario de la Costa.

Cortizo Álvarez, T., Trejo Gómez, E., Andrade Romo, E., Alonso González, M. L. y Chávez Dagostino, R. M. (2012). DINAMISMO. Las dinámicas demográfica y urbana en la Costa Oriental de Asturias y en Bahía de 
Banderas. En F. J. Núñez Cornú y F. Rodríguez Gutiérrez, Gestión integrada de paisajes litorales. Hacia una metodología comparativa. Caso Asturias, España, y Bahía de Banderas, México (pp. 25-64). México: Plaza y Valdés Editores.

Cronista oficial de Bahía de Banderas. (2016). Datos históricos del área de Nuevo Vallarta. México: Ciudad del Deporte de Bahía de Banderas.

Cruz Coria, E., Zizumbo Villarreal, L. y Monterroso Salvatierra, N. (2011). Espacio social, penetración del capital, subsunción del espacio, paisaje, Puerto Morelos, Quintana Roo. Diálogos. Revista Electrónica de Historia, 12(1), 51-57.

Cruz González, D. (2015). Procesos de desposesión a través del turismo en Puerto Vallarta, Jalisco, México (1970-2010) (Tesis de licenciatura). Guadalajara: Universidad de Guadalajara, Centro Universitario de la Costa.

Dávila López, A. (2014). Centros integralmente planeados (CIPs) en México: las piezas del proyecto turístico de Fonatur. En Seminario Internacional de Investigación en Urbanismo. Universidad Politécnica de Cataluña, Departamento de Urbanismo y Ordenación del Territorio, Barcelona.

Echeverría, B. (2012). Valor de uso y utopía. México: Siglo XXI Editores.

El Día. (1981). Ejemplo de ineptitud burocrática el hotel ejidal de Bucerías. El Día. El Informador. (1977). Desaparece el FONAJE; perdió \$1,500 Millones. El Informador, pp. 1, 3. Recuperado de http://hemeroteca.informador.com.mx [2017, 16 de abril].

Enciso, A. (2005). La Escalera Náutica, proyecto fantasma. La Jornada. Recuperado de http://www.jornada.unam.mx/2005/05/23/index.php? section $=$ politica\&article $=048 \mathrm{n} 1$ pol $[2017,13$ de enero $]$.

Fonatur (2006a). Proyecto Mar de Cortés. México: Autor.

Fonatur (2006b). Planeación de centros turísticos, la experiencia y práctica. México: Autor.

García Rivera, J. D. (1986). Bahía de Banderas: lucha política y desarrollo regional, 1970-1984 (Tesis de licenciatura en Sociología). Naucalpan, Estado de México: Universidad Nacional Autónoma de México, Facultad de Estudios Superiores Acatlán.

Gibson, C. (2009). Geographies of tourism: Critical research on capitalism and local livehoods. Progress in Human Geography, 33, 527-534.

Gobierno federal. (2016). Fondos y fideicomisos de fomento económico. México: 
Autor. Recuperado de https://www.gob.mx/cms/uploads/attachment/file/56050/sector31.pdf [2017, 15 de marzo].

Gobierno Municipal de Bahía de Banderas. (2014). Plan de Desarrollo Municipal de Bahía de Banderas 2014-2017. Recuperado de https://www. bahiadebanderas.gob.mx/transparencia/6/plandesarrollo/PlanDesarro2014-17.pdf [2017, 18 de agosto].

Guzmán Mejía, R. y Anaya Corona, M. C. (2011). Puerto Vallarta y sus satélites: oscilaciones de homeostasis en un destino de ocio. México: Universidad de Guadalajara.

Haesbaert, R. (2011). El mito de la desterritorialización: Del fin de los territorios a la multiterritorialidad. México: Siglo XXI Editores.

Inda, M. T. y Santamaría Gómez, A. (2015). Los Centros Integralmente Planeados (CIP’S) en México. Rev. Latino-Am. Turismología, 1(1), 36-53.

Instituto Nacional de Estadística y Geografía. (2009). Prontuario de información geográfica de los Estados Unidos Mexicanos Bahía de Banderas Nayarit. México: Autor.

Instituto Nacional de Estadística y Geografía. (2010). Censo de Población y Vivienda 2010. México: Autor.

Instituto Nacional de Estadística y Geografía. (2016). Anuario estadístico y geográfico de Nayarit 2016. México: Autor.

Jiménez, A. (2010). Cadenas hoteleras. Estrategias y territorio en el Caribe mexicano. México: Porrúa.

Lanfant, M. F. (1980). Introducción: El turismo en el proceso de internacionalización. Revista Internacional de Ciencias Sociales, 32(1), 14-45.

López Guerrero, L., Chávez Dagostino, R. M. y Moncada Cooley, R. (2001-2002). Un recorrido por la Bahía de Banderas de norte a sur. Mexicoa, 3(1-2).

Luna Jiménez, P. (1993). Vallarta y su región durante la primera mitad del siglo xx. En J. Olveda, Una aproximación a Puerto Vallarta. México: Doble Luna Editores e Impresores.

Marín Guardado, G. (2009). Turismo: globalización y desarrollo local: Puerto Vallarta y los retos del porvenir. Estudios Demográficos y Urbanos, 24(1), 219-247.

Martínez Hernández, V. (2009). La urbanización del suelo ejidal, o de cómo la "irregularidad" se convirtió en la "regularidad" para acceder a la tie-

rra. En P. Núñez Martínez y R. Rodríguez Carranza (coords.), Sociedad 
y economía. Estudios sobre Puerto Vallarta y su región (pp. 189-211). México: Universidad de Guadalajara, Centro Universitario de la Costa. Martínez Rangel, R. y Soto Reyes, E. (2012). El consenso de Washington: la instauración de las políticas neoliberales en América Latina. Política y Cultura, 37, 35-64.

Monterroso Salvatierra, N. y Zizumbo Villarreal, L. (2009). La reconfiguración neoliberal de los ámbitos rurales a partir del turismo. ¿Avance o retroceso? Convergencia. Revista de Ciencias Sociales, 16(50), 133-164.

Munguía Fregoso, C. (1994). Panorama histórico de Puerto Vallarta y de la Bahía de Banderas. Guadalajara: Gobierno de Jalisco-H. Ayuntamiento de Puerto Vallarta, Secretaría de Cultura.

Munguía Fregoso, C. (1997). Panorama histórico de Puerto Vallarta y de la Bahía de Banderas. México: ALTEGRAF.

Navarro Trujillo, M. L. (2015). Luchas por lo común. Antagonismo social contra el despojo capitalista de los bienes naturales en México. México: Bajo Tierra Ediciones/Benemérita Universidad Autónoma de Puebla.

Noorloos, F. (2013). ¿Un lugar en el sol para quién? El turismo residencial y sus consecuencias para el desarrollo equitativo y sostenible en Guanacaste. Alba Sud. Opiniones en Desarrollo, 15, 1-49.

Novedades. (1979). Siguen las quejas contra el FIBABA. Novedades.

Olivera Lozano, G. (2005). La reforma al artículo 27 constitucional y la incorporación de las tierras ejidales al mercado legal de suelo urbano en México. Revista Electrónica de Geografía y Ciencias Sociales, 9, 194(33). Recuperado de http://www.ub.edu/geocrit/sn/sn-194-33.htm. http:// dx.doi.org/B. 21.741-98 [2017, 15 de marzo].

Osorio, J. (2014). El Estado en el centro de la mundialización: la sociedad civil y el asunto del poder. México: Fondo de Cultura Económica.

Palafox Muñoz, A. (2011). El turismo como eje de acumulación y factor de transformación del paisaje en Cozumel, México (Tesis de doctorado). México: Universidad Autónoma del Estado de México.

Palafox Muñoz, A. (2013). El turismo como eje de acumulación. Nómadas, núm. especial, 1-14.

Palafox Muñoz, A., Zizumbo Villarreal, L. y Arriaga Álvarez, E. (2010). El turismo como eje de acumulación: caso del sector hotelero en México. Multiciencias, 2(10), 193-201. 
Periódico Oficial. Órgano del Gobierno del Estado de Nayarit. (17 de diciembre de 2005). Plan de Desarrollo Municipal de Bahía de Banderas, Nayarit; 2005-2008. Recuperado de http://www.ordenjuridico.gob.mx/Documentos/Eliminados/wo23760.pdf [2017, 17 de febrero].

Real Carranza, M., Olivarría Zepeda, M. Y. y Pacheco, J. (2010). Expropiación y despojo ejidal, el proceso de transformación. ¿Desarrollo turístico en Nayarit? Ponencia presentada en el VIII Congreso Latinoamericano de Sociología Rural, Porto de Galinhas.

Rodríguez Wallenius, C. (2015). Geopolítica del desarrollo local. Campesinos, empresas y gobiernos en la disputa por territorios y naturales en el México rural. México: Universidad Autónoma Metropolitana/Ítaca.

Roux, R. (2005). El príncipe mexicano: subalternidad, historia y Estado. México: Ediciones Era.

Secretaría de Desarrollo Social. (2010). Informe anual sobre la situación de pobreza y rezago social. México: Secretaría de Desarrollo Social/Consejo Nacional de Evaluación de la Política de Desarrollo Social. Recuperado de https://www.gob.mx/cms/uploads/attachment/file/45864/ Nayarit_020.pdf [2017, 23 de mayo].

Secretaría de Turismo. (2013). Encuesta Nacional de Gasto Turístico en los Hogares 2013. México: Autor. Recuperado de http://www.datatur.Sectur. gob.mx/Documentos \% 20Publicaciones/ENGATURH_2013.pdf [2017, 19 de agosto].

Secretaría de Turismo. (2016). Anuarios estadístico y geográfico de Nayarit 2016. México: Autor. Recuperado de http://www.datatur.Sectur.gob.mx/ ITxEF_Docs/NAY_ANUARIO_PDF16.pdf [2017, 18 de agosto].

Secretaría del Patrimonio Nacional. (miércoles 18 de noviembre de 1970). Decreto que declara de utilidad pública el desarrollo habitacional y turístico en los terrenos que circundan la Bahía de Banderas, ubicados en las costas de los Estados de Nayarit y Jalisco y el mejoramiento de varios centros de población, para lo cual se expropian en favor del Gobierno Federal, varias superficies ejidales del Municipio de Compostela, Nay., etc. Diario Oficial. Órgano del Gobierno Constitucional de los Estados Unidos Mexicanos, CCCIII(15), 4-5. Recuperado de http://www.dof. gob.mx/nota_to_imagen_fs.php?cod_diario $=203682$ \&pagina $=$ $4 \&$ seccion $=0$ [2017, 25 de abril] . 
Trejo, R. (2012). Despojo capitalista y privatización en México 1982-2010. México: Impresiones y Acabados Finos Amatl.

Turner, L. y Ash, J. (1991). La horda dorada: el turismo internacional y la periferia del placer. Madrid: Endymion.

Vilchis Onofre, A., Zizumbo Villarreal, L., Monterroso Salvatierra, N., Arriaga Álvarez, E. G. y Palafox Muñoz, A. (2016). Dinámicas capitalistas para la acumulación por despojo. Revista de Ciencias Sociales, 1(151), 31-41. 